\title{
30 year old woman with possible Creutzfeldt-Jakob Disease initially presenting with psychiatric symptoms: a case report Theodoros Papaslanis*, Panagiotis Karakasis, Antonios Hatzimanolis, Panagiotis Kostaras, Maria Maltezou and Gregorios Cheilakos
}

Address: Department of Neurology, 1st Hospital of Social Security Services, Athens, Greece

* Corresponding author

from International Society on Brain and Behaviour: 3rd International Congress on Brain and Behaviour

Thessaloniki, Greece. 28 November - 2 December 2007

Published: 17 April 2008

Annals of General Psychiatry 2008, 7(SuppI I):SI 22 doi:I0.I I86/I744-859X-7-SI-SI 22

This abstract is available from: http://www.annals-general-psychiatry.com/content/7/SI/SI 22

(c) 2008 Papaslanis et al.; licensee BioMed Central Ltd.

\section{Background}

Creutzfeldt-Jakob disease is a rare neurodegenerative disorder that belongs to the so called transmissible spongiform encephalopathies. Four types of the disease are recognized today: The sporadic form, responsible for over $80 \%$ of all cases, the familial, responsible for about $10 \%$ of cases, the iatrogenic and finally the variant form.

\section{Materials and methods}

We report a case of a thirty year old female Caucasian woman initially presenting with psychiatric symptoms.

\section{Results}

The patient's problems had begun six months prior to hospital admission with symptoms of disorientation in place and time and behavioral disturbances. She was treated initially as a psychiatric outpatient receiving medication. After 4 months of unsuccessful treatment she was hospitalized and subjected to 16 E.C.T. sessions. About 2 months after E.C.T., the patient was admitted to our hospital with neurological symtomatology (gait and speech disturbances). Biochemical examination, E.E.G and lumbar puncture (including protein 14-3-3 assay) were inconclusive, while brain MRI revealed brain atrophy and high signal intensity in the region of basal ganglia, imaging suggestive of Creutzfeldt-Jakob Disease. 22 months after initial presentation the patient is in a state of akinetic mutism.

\section{Conclusions}

To our knowledge this is the first report presenting in Greece concerning possible Creutzfeldt-Jakob Disease in such a young person. The initial presentation with pure psychiatric symptoms is also of interest, while the time elapsed since the presentation of neurological symtomatology is considered to be quite long.

\section{References}

I. Zerr I, Poser S: Clinical Diagnosis and Differential Diagnosis of CJD and vCJD. APMIS 2002, I I 0:88-98.

2. Beisel CE, Morens DM: Variant Creutzfeldt-Jakob Disease and the Acquired and Transmissible Spongiform Encephalopathies. Clinical Infectious Diseases 2004, 38:697-704.

3. Collins SJ, Lawson VA, Masters CL: Transmissible spongiform encephalopathies. Lancet 2004, 363:5I-6I.

4. Van Everbroeck B, Dobbeleir I, De Waele M, De Deyn P, Martin J-J, Cras P: Differential diagnosis of 201 possible CreutzfeldtJakob disease patients. J Neurol 2004, 25I:298-304. 